\title{
Homeobox Protein Goosecoid
}

National Cancer Institute

\section{Source}

National Cancer Institute. Homeobox Protein Goosecoid. NCI Thesaurus. Code C50884.

Homeobox protein goosecoid (257 aa, $28 \mathrm{kDa}$ ) is encoded by the human GSC gene.

This nuclear transcription factor regulates the production of chordin and belonds to the paired homeobox family. 